\title{
Asthma aggravation, combustion, and stagnant air
} Gary Norris, Timothy Larson, Jane Koenig, Candis Claiborn, Lianne Sheppard,
Dennis Finn meteorology with a knowledge of specific air pollution point sources.

Other studies have combined meteorology with chemical composition of particulate matter. For instance, factor analysis with a varimax rotation of the particulate matter composition collected from 1957 to 1961 from 30 cities across the USA found seven factors representing heavy industry or steel production, internal combustion engines, coal combustion, possible gas production, a zinc-tin factor, plating, and copper. ${ }^{6} \mathrm{Gatz}^{7}$ included meteorological variables (mean wind speed, maximum wind speed, ventilation rate, wind direction, rain) along with the composition of particulate matter in a factor analysis to help identify sources. In that study wind direction was the only meteorological variable that was correlated with particulate matter concentration. Thurston and Spengler ${ }^{8}$ used factor analysis with a varimax rotation separately on particulate matter composition and meteorological parameters. The sources representing the motor vehicle factor (lead, bromine) were significantly correlated with the meteorological component representing poor dispersion. Lewis and coworkers ${ }^{9}$ used carbon monoxide in place of lead as a tracer of motor vehicles in a study of particulate matter composition in Denver. They found a high correlation between carbon monoxide and lead $\left(R^{2}=0.91\right)$. Similar motor vehicle apportionment results were seen when either carbon monoxide or lead were used in a multiple linear regression receptor model. ${ }^{10}$

Recent studies have focused on the association between general levels of air pollution in urban areas and visits to the emergency department for asthma. A number of studies have found a significant association between increased levels of particulate matter (PM) and increased visits to the emergency department for asthma. ${ }^{11-15}$ The identity of the specific components of PM responsible for the observed association remains unclear. In the present study we have used our ability to quantify the relevant meteorology associated with increased pollution events to identify more specifically those air pollutants associated with emergency department visits for asthma in Spokane and Seattle, Washington, USA.

Dr J Q Koenig, Department of Environmental Health, 357234, University of Washington, Seattle, Washington 98195, USA

Received 27 May 1998 Returned to authors 31 July 1998

Revised version received

21 February 2000

Accepted for publication

21 February 2000
Keywords: asthma; air stagnation; wind speed; air pollution ticulate levels of organic and elem carbon, and was or with asthma aggravation than any one of the measured pollutants.

(Thorax 2000;55:466-470)

Previous studies have shown that certain meteorological conditions are useful for identifying sources of particulate matter which are responsible for outbreaks of asthma. ${ }^{12}$ Point sources of particulate matter from grain ${ }^{3}$ and soybean dusts ${ }^{45}$ have been identified as being responsible for asthma outbreaks. These studies demonstrate the usefulness of combining

\section{Methods}

SPOKANE

The study was conducted in Spokane, Washington, a city located in a river valley in an arid agricultural region. According to a 1990 census the population of the study area including the city of Spokane and surrounding areas is 300 000. In Spokane the major sources of particulate matter are varied and include wood 


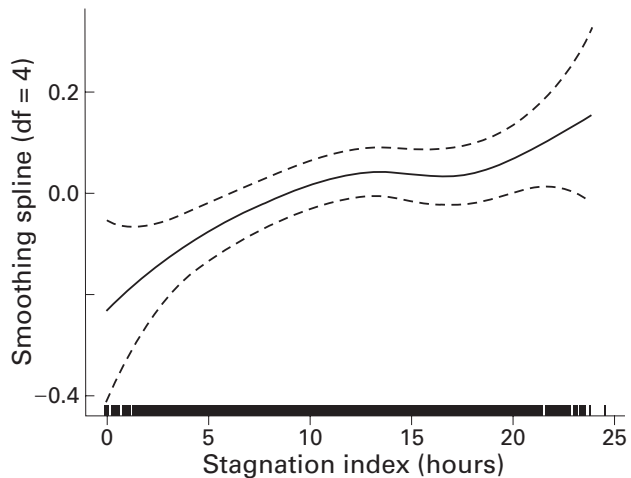

Figure 1 Smooth function of the stagnation index regressed on visits to the emergency department for asthma by non-elderly subjects after adjustment for day of week, time trends, temperature, and dew point temperature. (The ordinate is the contribution to the additive predictor in units of $\left(\log _{e}\right.$ (visits/day)).

burning, grass field burning, automobiles, heavy duty diesel vehicles, resuspended road dust, and dust storms from nearby arid regions of central Washington.

Measurements of atmospheric pollutants and meteorological variables were obtained from an ongoing Spokane PM health effects study, Washington State Department of Ecology, and the National Climatic Data Center. A preliminary examination of the meteorology indicated that an increased occurrence of low wind speeds was associated with increases in the concentrations of combustion related pollutants. To quantify this association we used a simple variable named the "stagnation persistence index" ${ }^{\prime 16}$ defined as the number of hours in the 24 hour day in which the wind speed is less than the 50th percentile of the hourly wind speed at that location. The 50th percentile was chosen to provide sufficient variation in this index to span the entire observed range of values between 0 and 23 . We averaged this index over three sites. The stagnation persistence index may reflect relative changes in urban pollution exposure levels better than traditional air pollutant measures at a given site because meteorology is a more regional variable. The correlation between the daily stagnation persistence index at any one site and the daily average value for all sites in the urban area was high ( $R$ varied between 0.90 and 0.94 for three Spokane sites).

Data on emergency department visits for asthma were obtained from four participating

Table 1 Distribution of health outcomes and selected atmospheric variables

\begin{tabular}{|c|c|c|c|c|c|c|c|c|}
\hline \multirow[b]{2}{*}{ Variable } & \multicolumn{4}{|c|}{ Spokane (1/95-3/97) } & \multicolumn{4}{|c|}{ Seattle $^{*}(9 / 95-12 / 96)$} \\
\hline & Mean & Min & $\operatorname{Max}$ & $\begin{array}{l}\% \\
\text { missing }\end{array}$ & Mean & Min & $\operatorname{Max}$ & $\begin{array}{l}\% \\
\text { missing }\end{array}$ \\
\hline Asthma & 3.2 & 0 & 12 & 0 & 1.9 & 0 & 9.0 & 0 \\
\hline Gastroenteritis & 2.9 & 0 & 11 & 0 & 1.4 & 0 & 10 & 0 \\
\hline Temperature $\left({ }^{\circ} \mathrm{C}\right)$ & 7.5 & -23.0 & 27.8 & 0 & 11.1 & -17.2 & 26.7 & 0 \\
\hline Dew point $\left({ }^{\circ} \mathrm{C}\right)$ & 1.1 & -23.0 & 13.9 & 0 & 6.4 & -13.6 & 16.7 & 0 \\
\hline $\mathrm{PM}_{10}\left(\mu \mathrm{g} / \mathrm{m}^{3}\right)$ & 27.9 & 4.7 & 186.4 & 0.4 & 21.5 & 8.0 & 69.3 & 3.8 \\
\hline $\mathrm{CO}(\mathrm{ppm})$ & 1.7 & 0.7 & 3.9 & 0 & 1.6 & 0.6 & 4.1 & 0 \\
\hline $\mathrm{SO}_{2}(\mathrm{ppb})$ & 2.4 & 0 & 13 & 28.8 & 5.8 & 1.0 & 21 & 2.5 \\
\hline Ozone (ppb) & 36.9 & 17.9 & 59.0 & 2 & 29.9 & 3.0 & 83 & $45^{\star \star}$ \\
\hline 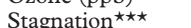 & 12.0 & 0 & 24.0 & 0 & 11.9 & 0 & 24 & 0 \\
\hline
\end{tabular}

$\star$ Young Pong et al. ${ }^{21}$

${ }^{\star \star} \mathrm{Ozone}$ is only measured from April to October in Seattle.

$\star \star \star$ Stagnation persistence index (see text) hospitals in Spokane. Approval for the use of anonymous hospital data for both cities was given by the University of Washington Human Subjects Office and the participating hospitals. The association between daily emergency department visits for asthma and the stagnation persistence index were examined.

SEATTLE

The results found in Spokane were then tested for comparison on data collected in previous research in Seattle, a coastal city located on Puget Sound. The population of the Seattle study area contributing cases to the emergency department data was approximately one million. In Seattle the major sources of particulate matter are wood burning, automobiles, heavy duty diesel vehicles, and resuspended road dust, but not grass field burning or dust storms. The Seattle study used data collected from September 1995 to December 1996 and was confined to asthma cases below the age of 18 years. Meteorological and air pollution data for Seattle were obtained from the Puget Sound Air Pollution Control Agency (now Puget Sound Clean Air Agency), Washington State Department of Ecology, and the National Climatic Data Center. Wind speed was averaged over four sites and emergency department visits for asthma were obtained from six participating hospitals. Data for factor analysis were available from a previous study conducted between July 1993 and June 1994 in Seattle.

\section{STATISTICS}

The daily emergency department visits for asthma were regressed on predictor and confounding variables using a semi-parametric Poisson regression model. As the daily emergency department asthma visits are count data and are also rare events, it is reasonable to assume (conditional on the covariates) that the counts have a Poisson distribution. The effect of air pollution on the increased number of visits to the emergency department for asthma is small and confounders such as season either obscure or inflate the small effect estimates. In order to evaluate the association between emergency department visits for asthma and air pollution, base models were created to control for potential systematic effects such as day of week, and confounding by seasonal trends, temperature, and dew point temperature. Separate base models were created for Spokane (subjects <65 years of age) and Seattle (subjects $<18$ years of age). Base models were constructed to adjust for potential confounding factors using day of week indicator variables, smooth functions for time trends, temperature, and dew point temperature (on previous day $\left.{ }^{11}\right)$. We chose a one day lag in both temperature and dew point temperature because they had the best combined fit. Using either a zero or one day lag in both of these variables did not affect the results. The degrees of freedom for the smoothing splines ${ }^{17}$ for temperature and dew point temperature were selected based on minimising the degrees of freedom adjusted deviance or Akaike Information Criteria (AIC).$^{18}$ AIC was used to help 
Table 2 Pearson correlations among pollutant variables in Spokane\# and Seattle, and among $\mathrm{PM}_{10}, \mathrm{SO}_{2}$ and $\mathrm{O}_{3}$ in Spokane

\begin{tabular}{|c|c|c|c|c|c|c|c|c|c|c|c|}
\hline & $\mathrm{SO}_{4}^{2-\star}$ & $K^{\star \star}$ & $\mathrm{NH}_{4}^{+}$ & $E C$ & $O C$ & Soil & $\mathrm{CO}$ & Stagnation $* * \star$ & $P M_{10}$ & $\mathrm{SO}_{2}$ & $\mathrm{O}_{3}$ \\
\hline \multicolumn{12}{|l|}{ Spokane } \\
\hline $\mathrm{SO}_{4}^{2-\star}$ & 1.00 & - & 0.60 & 0.15 & 0.33 & 0.26 & 0.23 & 0.38 & & & \\
\hline$K^{\star \star}$ & & 1.00 & - & - & - & - & - & - & & & \\
\hline $\mathrm{NH}_{4}^{+}$ & & & 1.00 & 0.27 & 0.37 & -0.05 & 0.29 & 0.30 & & & \\
\hline EC & & & & 1.00 & 0.45 & -0.01 & 0.26 & 0.27 & & & \\
\hline OC & & & & & 1.00 & 0.08 & 0.46 & 0.53 & & & \\
\hline Soil & & & & & & 1.00 & 0.03 & 0.10 & & & \\
\hline $\mathrm{CO}$ & & & & & & & 1.00 & 0.53 & & & \\
\hline Stagnation $\star \star \star \star$ & & & & & & & & 1.00 & & & \\
\hline \multicolumn{12}{|l|}{ Seattle } \\
\hline $\mathrm{SO}_{4}^{2-\star}$ & 1.00 & 0.38 & 0.95 & 0.50 & 0.41 & 0.08 & 0.52 & 0.50 & & & \\
\hline $\mathrm{K}^{\star \star}$ & & 1.00 & 0.43 & 0.91 & 0.94 & 0.07 & 0.77 & 0.55 & & & \\
\hline $\mathrm{NH}_{4}^{+}$ & & & 1.00 & 0.52 & 0.43 & -0.05 & 0.56 & 0.54 & & & \\
\hline EC & & & & 1.00 & 0.91 & 0.10 & 0.86 & 0.65 & & & \\
\hline OC & & & & & 1.00 & 0.27 & 0.84 & 0.62 & & & \\
\hline Soil & & & & & & 1.00 & 0.12 & 0.08 & & & \\
\hline $\mathrm{CO}$ & & & & & & & 1.00 & 0.86 & & & \\
\hline Stagnation $\star \star \star \star$ & & & & & & & & 1.00 & & & \\
\hline \multicolumn{12}{|l|}{ Spokane } \\
\hline $\mathrm{PM}_{10}$ & & & & & & & & & 1.00 & 0.45 & 0.27 \\
\hline $\mathrm{SO}_{2}$ & & & & & & & & & & 1.00 & 0.16 \\
\hline $\mathrm{O}_{3}$ & & & & & & & & & & & 1.00 \\
\hline
\end{tabular}

$\mathrm{EC}=$ elemental carbon; $\mathrm{OC}=$ organic carbon.

\#Data from Haller et al. ${ }^{22}$

$\star$ Elemental sulphur.

$\star \star \mathrm{K}$ is measured as soluble potassium.

$\star \star \star$ Stagnation persistence index (see text).

determine the appropriate degrees of freedom for a smooth function where the smallest AIC is desired. ${ }^{19}$ The AIC worked well with the temperature and dew point temperature smoothing splines in these analyses, but tended to overfit the time trends which caused autocorrelation in the residuals. The degrees of freedom (df) for the time trends were selected to reduce the autocorrelation in the residuals. The Spokane base model used a smoothing spline of $32 \mathrm{df}$ to adjust for time trends for the 27 month data set. The temperature and dew point temperature smoothing splines had a minimum AIC at 3 and $4 \mathrm{df}$, respectively. The Seattle base model used a smoothing spline with $5 \mathrm{df}$ to adjust for time trends and the temperature and dew point temperature had a minimum AIC at 3 and $2 \mathrm{df}$, respectively. The difference in the degrees of freedom for time trends for the Spokane and Seattle data is caused by differences in the number of seasons which the analyses covered and the lower seasonal variability in the Seattle data set.

After the base models were created, the air pollution exposure variables were evaluated by adding them individually into the model. Models were also evaluated which had multiple

Table 3 Factor loadings from 24 hour averages

\begin{tabular}{|c|c|c|c|c|c|c|}
\hline & \multicolumn{3}{|c|}{$\begin{array}{l}\text { Eigen value } \\
\text { (Seattle, WA (7/93-6/94)) }\end{array}$} & \multicolumn{3}{|c|}{$\begin{array}{l}\text { Eigen value } \\
\text { (Spokane, WA }(1 / 95-3 / 97)) \dagger\end{array}$} \\
\hline & 4.0 & 2.2 & 1.0 & 3.0 & 1.5 & 1.2 \\
\hline \multicolumn{7}{|c|}{$\mathrm{PM}_{2.5}$ filter measurements: } \\
\hline $\mathrm{SO}_{4}^{2-}$ & 0.24 & 0.95 & 0.06 & 0.13 & 0.89 & 0.19 \\
\hline $\mathrm{K} \ddagger$ & 0.94 & 0.13 & -0.01 & - & - & - \\
\hline $\mathrm{NH}_{4}^{+}$ & 0.29 & 0.94 & -0.08 & 0.26 & 0.85 & -0.16 \\
\hline $\mathrm{EC}$ & 0.92 & 0.27 & 0.02 & 0.74 & 0.06 & -0.02 \\
\hline $\mathrm{OC}$ & 0.94 & 0.17 & 0.19 & 0.82 & 0.20 & 0.07 \\
\hline Soils & 0.08 & -0.01 & 0.99 & 0.00 & 0.03 & 0.99 \\
\hline Carbon monoxide & 0.87 & 0.37 & 0.04 & 0.66 & 0.11 & -0.08 \\
\hline Stagnation ${ }^{\star}$ & 0.68 & 0.45 & 0.01 & 0.72 & 0.25 & 0.06 \\
\hline
\end{tabular}

†Data from Haller $e t$ al. $^{22}$

¥Water soluble potassium.

(Defined as a function of $\mathrm{Si}, \mathrm{Ca}, \mathrm{Fe}, \mathrm{Ti}^{23}$

*Stagnation persistence index (see text).

$\mathrm{EC}=$ elemental carbon; $\mathrm{OC}=$ organic carbon. exposure variables. Final models were adjusted for overdispersion or for the variance exceeding the mean. The Spokane and Seattle residuals had overdispersion parameters of 1.08 and 1.12 , respectively. In addition, the assumption of a linear dose-response relationship was evaluated using a smooth function. Linearity was assumed if a straight line could be fit within the $95 \%$ confidence limits of the smooth function (see, for example, the linear effect of stagnation shown in fig 1). All analyses were conducted with the S-plus statistical package ${ }^{20}$ using a generalised additive model.

\section{Results}

Table 1 shows the distribution of the variables used in the analysis and table 2 summarises the pairwise correlation coefficients for the measured pollutant variables (including stagnation) in both Spokane and Seattle. Table 3 summarises the major features of the atmospheric variability common to both cities as quantified by factor analysis: (1) products of incomplete combustion including fine particulate elemental carbon (EC), organic carbon (OC), and gaseous carbon monoxide (CO); (2) soil derived components; and (3) fine particle sulphate and ammonium compounds. The factor loadings were also examined as a function of wind direction. There is no obvious variation in the combustion-stagnation factor with wind direction.

The stagnation persistence index was positively associated with increased numbers of visits to the emergency department for asthma in both single and multi-pollutant models (tables 4 and 5). These models were evaluated to determine if the relative rate of emergency department visits per increment of stagnation persistence index decreased with the addition of the traditional air pollutant measures. An interquartile increase in the exposure variable was used in the calculation of the relative rate to allow for a comparison of the different exposure 
Table 4 Association between exposure variables and emergency department asthma visits for Spokane

\begin{tabular}{|c|c|c|c|c|}
\hline & Increase & $R R^{\star}$ & $\begin{array}{l}95 \% \text { confidence } \\
\text { interval }\end{array}$ & $\begin{array}{l}\text { Correlation between } \\
\text { exposure variables }\end{array}$ \\
\hline \multicolumn{5}{|l|}{ Single pollutant } \\
\hline Stagnation ${ }^{\star \star}$ & 10.6 hours & 1.12 & 1.05 to 1.19 & \\
\hline $\mathrm{PM}_{10}$ & $21.4 \mu \mathrm{g} / \mathrm{m}^{3}$ & 1.01 & 0.95 to 1.07 & \\
\hline Carbon monoxide & $0.68 \mathrm{ppm}$ & 1.06 & 1.00 to 1.11 & \\
\hline Sulphur dioxide $e^{\star \star \star}$ & $8 \mathrm{ppb}$ & 1.04 & 1.01 to 1.07 & \\
\hline \multicolumn{5}{|l|}{ Multi-pollutant } \\
\hline $\mathrm{PM}_{10}$ & $21.4 \mu \mathrm{g} / \mathrm{m}^{3}$ & 0.94 & 0.88 to 1.00 & 0.53 \\
\hline Stagnation ${ }^{\star \star}$ & 10.6 hours & 1.17 & 1.08 to 1.27 & \\
\hline Carbon monoxide & $0.68 \mathrm{ppm}$ & 0.97 & 0.89 to 1.05 & 0.53 \\
\hline Stagnation ${ }^{\star \star}$ & 10.6 hours & 1.15 & 1.04 to 1.27 & \\
\hline Sulphur dioxide $e^{\star \star \star}$ & $8 \mathrm{ppb}$ & 1.02 & 0.98 to 1.05 & 0.44 \\
\hline Stagnation $\star \star$ & 10.6 hours & 1.10 & 1.02 to 1.18 & \\
\hline
\end{tabular}

${ }^{\star}$ Relative rates reported for a three day lag; units are interquartile range (25th-75th percentile). ${ }^{\star \star}$ Stagnation persistence index (see text).

$\star \star \star$ Maximum daily one hour average.

Table 5 Association between exposure variables and emergency department asthma visits for Seattle\#

\begin{tabular}{|c|c|c|c|c|}
\hline & Increase & $R R^{\star}$ & $\begin{array}{l}95 \% \text { confidence } \\
\text { interval }\end{array}$ & $\begin{array}{l}\text { Correlation between } \\
\text { exposure variables }\end{array}$ \\
\hline \multicolumn{5}{|l|}{ Single pollutant } \\
\hline Stagnation $\star \star$ & 9.5 hours & 1.21 & 1.09 to 1.35 & \\
\hline $\mathrm{PM}_{10}$ & $11.7 \mu \mathrm{g} / \mathrm{m}^{3}$ & 1.11 & 1.02 to 1.20 & \\
\hline Carbon monoxide & $0.58 \mathrm{ppm}$ & 1.11 & 1.03 to 1.19 & \\
\hline Sulphur dioxide ${ }^{\star \star \star}$ & $12 \mathrm{ppb}$ & 1.02 & 0.96 to 1.10 & \\
\hline \multicolumn{5}{|l|}{ Multi-pollutant } \\
\hline $\mathrm{PM}_{10}$ & $11.7 \mu \mathrm{g} / \mathrm{m}^{3}$ & 1.03 & 0.93 to 1.14 & 0.54 \\
\hline Stagnation ${ }^{\star \star}$ & 9.5 hours & 1.19 & 1.04 to 1.35 & \\
\hline Carbon monoxide & $0.58 \mathrm{ppm}$ & 1.01 & 0.91 to 1.13 & 0.64 \\
\hline Stagnation $\star \star$ & 9.5 hours & 1.20 & 1.03 to 1.39 & \\
\hline Sulphur dioxide $e^{\star \star \star}$ & $12 \mathrm{ppb}$ & 1.02 & 0.95 to 1.09 & 0.07 \\
\hline Stagnation $\star \star$ & 9.5 hours & 1.21 & 1.09 to 1.35 & \\
\hline
\end{tabular}

\#Data from Young Pong. ${ }^{21}$

${ }^{\star}$ Relative rates reported for a three day lag; units are interquartile range (25th-75th percentile). ${ }^{\star \star}$ Stagnation persistence index (see text).

$\star \star \star$ Maximum daily one hour average.

measures in the same air shed. The multipollutant models used exposure variables that are moderately correlated (shown in table 2). The use of correlated exposure variables complicates the interpretation of the relative rate, but the multi-pollutant models show the robustness of the stagnation persistence index. No statistically significant associations were found between the stagnation persistence index and a control diagnosis (gastroenteritis). An analysis by season was performed and the association between asthma and the stagnation persistence index was found to be strongest in the spring and autumn.

Several different adjustments for temperature and dew point temperature were evaluated to determine whether the meteorological adjustments were causing the association between the stagnation persistence index and emergency department visits for asthma but no effect was found.

The stagnation persistence index and the maximum one hour daily sulphur dioxide concentration were associated with emergency department visits for asthma by non-elderly subjects in Spokane (table 4). When the traditional pollutant measures were combined one at a time with the stagnation persistence index in various two-pollutant models (table 4) this index remained significant while $\mathrm{PM}_{10}$, carbon monoxide, and sulphur dioxide were not significant.

In Seattle the stagnation persistence index, $\mathrm{PM}_{10}$, and carbon monoxide were significantly associated with visits by adolescents to the emergency department for asthma (table 5). The stagnation persistence index remained significant in various two-pollutant models (table 5) while carbon monoxide, $\mathrm{PM}_{10}$, and sulphur dioxide were not significant.

\section{Discussion}

The stagnation persistence index used in this study was strongly associated with emergency department visits for asthma in two cities. We do not suggest that low wind speed per se is a trigger for asthma aggravation. However, based on the factor analysis, we suggest that the associated build up of airborne irritants under increasingly stagnant air is a logical trigger. Our results show that the products of incomplete combustion are the air pollutants associated with increases in emergency department visits for asthma. Our study also shows similar associations between the stagnation persistence index and emergency department visits for asthma in two dissimilar cities, one in a semi-arid region and one in a coastal area. Exactly which combustion related pollutants are responsible would be difficult to discern from these data, given that the associated meteorology is a strong predictor of asthma aggravation. It could be that the triggering agent or agents were not even measured in this study - for example, combustion derived organic vapours or aeroallergens-but are strongly correlated with the occurrence of stagnant air and the measured concentrations of combustion products. However, based on our factor analysis, it is also clear that the two other independent chemical features-soilderived particles and sulphate compoundsare not driving the observed association.

The relative strength of the association with the stagnation persistence index may result in part from the high degree of spatial correlation of this index across the urban area, implying a better predictor of increased air pollution exposure to the urban population as a whole. This categorical index is precisely measured and also has an upper limit (all hours of the 24 hour day have wind speeds lower than the 50\% annual value). In the worst case a stagnant day with an average of 24 hours for the stagnation persistence index predicts an increase in visits to the emergency department for asthma of $28 \%$ and $63 \%$ for Spokane and Seattle, respectively. This implies that a consecutive multi-day index also needs to be explored in this regard. However, the high correlation between the stagnation persistence index and the air pollutant measures in our study areas (including carbon monoxide, organic carbon, and elemental carbon) complicates the interpretation of this index in a multi-pollutant model of health outcomes.

Pope and Kalkstein ${ }^{1}$ used synoptic weather categories to control for meteorological confounders and produced a small, non-significant change in the association between $\mathrm{PM}_{10}$ and 
mortality relative to a model that did not include these weather categories. In contrast, our stagnation persistence index is highly correlated with certain air pollutant levels and, because of its uniformity over the urban area, is a useful urban air pollution index. However, it should not be used alone as a predictor of health effects. We use it as part of a set of multivariate exposure parameters that include both pollutant levels and meteorological factors. Using the stagnation persistence index as part of a multivariate parameter allows us to acknowledge the correlation between meteorology and pollution level and to interpret the association between stagnation and asthma. In this case, the multivariate feature that is highly correlated with the stagnation persistence index is a combustion related feature. The fact that stagnation was correlated with only one of the three observed multivariate features is also important. Had it been correlated with two or more features, it would have been more difficult to interpret the source mix associated with the observed effect.

Interestingly, mean daily wind speed is not a good predictor of the levels of any air pollutants in Spokane so we did not include mean daily wind speed in our final models. Our stagnation persistence index is a surrogate measure of air pollution and therefore lacks chemical specificity (and is therefore also difficult to link to prevention measures). However, use of this index in conjunction with air pollution measurements allows us to define and interpret multivariate exposure features that are specifically related to certain source categories-for example, ground level sources of combustion.

A major limitation to the use of a stagnation persistence index in the epidemiology of air pollution is that it does not identify specific pollutants. This limitation is balanced somewhat by the fact that the index is readily available in all major urban areas. It would be interesting to know whether the stagnation persistence index in other cities is also associated with emergency department visits for asthma. Although most urban areas in the USA have routine air pollution monitoring at a minimum of one site, all urban areas have a number of routine wind speed monitors with a large historical record. If associations with health outcomes are discovered in a given urban area, special studies of limited duration could be conducted to identify the associations of this index with specific chemical components of the complex air pollution mixture. The stagnation persistence index, along with particulate composition data, points to components of combustion derived air pollution as sources exacerbating asthma. It is likely that the stagnation persistence index is a surrogate for a complex mixture (pollutant cocktail) of combustion derived pollutants. On the other hand, it is possible that stagnation is a surrogate for an unmeasured and unidentified pollutant that functions as a trigger for asthma aggravation.

This research was funded by the Washington State Department of Ecology, the US Environmental Protection Agency, the American Lung Association of Washington, and the EPA Northwest Center for Particulate Matter and Health. The results discussed here do not necessarily reflect the policies of these agencies. The authors thank Wendy Sullivan for assistance with data analysis and Natalie Young Pong for asthma ED data from Seattle.

1 Pope CA, Kalkstein LS. Synoptic weather modeling and estimates of the exposure-response relationship between daily mortality and particulate air pollution. Environ Health Perspect 1996;104:414-20.

2 Pope CA III, Hill RW, Villegas GM. Particulate air pollution and daily mortality on Utah's Wasatch front. Environ Health Perspect 1999;107:567-73.

3 Cowan DW, Thompson HJ, Paulus $\mathrm{H}$, et al. Bronchial asthma associated with air pollutants from the grain industry. 7 Air Pollution Control Assoc 1963;13:546-52.

4 Anto JM, Sunyer J. A point source asthma outbreak. Lancet 1986; ;: $900-3$.

5 White MC, Etzel RA, Olson D, et al. Reexamination of epidemic asthma in New Orleans, Louisiana, in relation to the presence of soy at the harbor. Am F Epidemiol 1997;145: $432-8$

6 Blifford HI, Meeker GO. A factor analysis model of large scale pollution. Atmos Environ 1967;1:147-57.

7 Gatz DF. Identification of aerosol sources in the St Louis area using factor analysis. $\mathcal{F}$ Appl Meteor $1978 ; 17: 600-8$.

8 Thurston GD, Spengler JD. A multivariate assessment of meteorological influences on inhalable particulate source impacts. F Climate Appl Meteor 1985;24:1245-56.

9 Lewis CW, Baumgardner RE, Stevens RK, et al. Receptor modeling study of Denver winter haze. Environ Sci Technol 1986;20:1126-35.

10 Kleinman MT, Pasternack BS, Wisenbud M, et al. Identifying and estimating the relative importance of sources of airborne particulates. Environ Sci Technol 1980;14:62-5.

11 Schwartz J, Slater D, Larson TV, et al. Particulate air pollution and hospital emergency room visits for asthma in tion and hospital emergency room visits for

12 Delfino RJ, Murphy-Moulton A M, Burnett RT, et al. Effects of air pollution on emergency room visits for respiratory illnesses in Montreal, Quebec. Am f Respir Crit Care Med 1997;155:568-76.

13 Castellsague J, Sunyer J, Saiz M, et al. Short-term ssociation between air pollution and emergency room visits for asthma in Barcelona. Thorax 1995;50:1051-6.

14 Ponka A. Asthma and low level air pollution in Helsinki. Arch Environ Health 1991;46:262-70.

15 Lipsett M, Hurley S, Ostro B. Air pollution and emergency room visits for asthma in Santa Clara County, California. Environ Health Perspect 1997;105:216-22.

16 Larson TV, Moseholm L, Slater D, et al. "Local background" levels of carbon monoxide in an urban area. Transportation Res A 1996;30:399-413.

17 Hastie TJ, Tibshirani RJ. Generalized additive models. New York: Chapman \& Hall, 1990.

18 Akaike H. Statistical predictor identification. Ann Inst Stat Math 1970;22:203-17.

19 Sheppard L, Levy D, Norris G, et al. Effects of ambient air pollution on nonelderly asthma hospital admissions in Seattle, Washington, 1987-1994. Epidemiology 1999;10: 23-30.

20 StatSci S-PLUS, StatSci, Seattle, Washington, 1993

21 Young Pong SN. Does air pollution aggravate childhood asthma in Seattle? Masters Thesis, University of Washington, Seattle, 1997.

22 Haller L, Claiborn C, Larson T, et al. Airborne particulate matter size distributions in an arid, urban area. $\mathcal{F}$ Air Waste Management Assoc 1999;49:161-8.

23 Malm WC, Sisler JF, Huffman D, et al. Spatial and seasonal trends in particle concentration and optical extinction in the United States. F Geophys Res 1994;99:1347-70. 